\title{
IN PLANE LOADED MASONRY WALLS: DEM \& FEM/DEM MODELS. A CRITICAL REVIEW
}

Daniele Baraldi ${ }^{1}$, Emanuele Reccia ${ }^{2}$, and Antonella Cecchi ${ }^{3}$

Department of Architecture Construction Conservation (DACC)

Università IUAV di Venezia

Dorsoduro 2206, 30123 Venezia, Italy

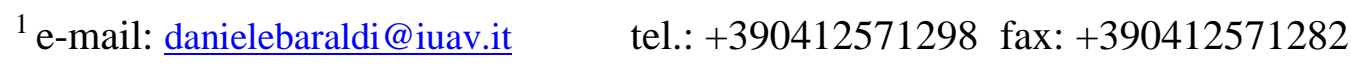

2 e-mail: emreccia@iuav.it

3 e-mail: cecchi@iuav.it

Keywords: Masonry Structures, Discrete Models, Discrete/Finite Element Models, Nonlinear Analysis, Mohr-Coulomb Yield Function.

\begin{abstract}
This work is dedicated to the assessment of the nonlinear behaviour of masonry panels with regular texture and subject to in-plane loads, by means of numerical pushover analysis and an analytical homogenized model. Two numerical models are considered and adopted for performing a set of numerical tests: a Discrete Model (DEM) developed by authors and a Discrete/Finite Element Model (FEM/DEM) frequently adopted in rock mechanics field and effectively extended to masonry structures. In both models the hypotheses of rigid blocks and elastic-plastic joints following a Mohr-Coulomb yield criterion are adopted.

The aim of this work is twofold: i) a comparison and a calibration of the numerical models, evaluating their effectiveness in determining ultimate loads and collapse mechanisms of masonry panels, by assuming a nonlinear homogenized model for regular masonry as reference solution; ii) the evaluation of sensitivity of masonry behaviour and numerical models to panel dimension ratio and to varying masonry texture. In a first case study, sliding collapse mechanisms changing to overturning collapse mechanisms for increasing panel and block height-to-width ratio are obtained and the results given by the numerical models turn out to be in good agreement. Furthermore, a second case study, dedicated to square panels supported at base ends and vertically loaded, shows different 'arch mechanisms' depending on block height-to-width ratio.
\end{abstract}




\section{INTRODUCTION}

Masonry is one of the more common structural materials in ordinary and monumental buildings in Italy and Europe, since it has been adopted for centuries up to present days. As well known, masonry is a composite or heterogeneous structural material obtained by assembling natural or artificial blocks by means of mortar layers or dry joints. Analytical and numerical modelling of such a material represents a research field that is continuously characterized by the proposition of new more or less detailed models, given that the assessment of masonry structural behaviour is fundamental for ensuring building safety condition and for restoration purposes.

A wide set of analytical and numerical models may be adopted for studying masonry material. Models may be distinguished for different aspects; for instance, the scale level considered, the type of actions adopted, and the type of analysis performed. This work is dedicated to the analysis of small/medium scale masonry specimens, subject to in-plane loads and nonlinear analyses are carried on by adopting models able to account for material heterogeneity.

In order to perform numerical or computer-aided analysis of masonry at small/medium scale, detailed models accounting for material heterogeneity may be taken into account and, for this purpose, discrete models [1] and heterogeneous finite element models [2,3] represent two main model categories that may be found in literature. However, continuous models accounting for masonry details at microstructure [4] represent a further important and effective tool for studying masonry behavior and innovative models, in this field of analysis, are continuously developed [5-8]. Focusing on discrete models, it must be pointed out that they represent a class of numerical models able to study the mechanical behaviour of systems made of particles, blocks or multiple bodies. This model type was introduced for modelling rocks $[9,10]$ and a computer code was also created for this purpose in plane case [11]. Discrete element models (DEMs) are characterized by two components: elements and contacts. Elements may be modelled as infinitely rigid bodies or may be considered as deformable bodies by adding strain deformation parameters to each block [12] or by subdividing them into Finite Elements (FEs). In both cases, the number of degrees of freedom needed for describing the model is larger with respect to the case of infinitely rigid bodies. Elements are subject to displacements and rotations that may become large during analysis, then DEMs are frequently formulated in the dynamic field and dynamic algorithms are adopted for obtaining numerical solutions; for instance, starting with a perturbation to the initial model and solving the equation of motion with a direct integration in time domain. Contacts between elements may be modelled with proper elements or by evaluating element overlapping, and in many cases they are often characterized by contact detection algorithms. 
Considering DEMs having elements subdivided into FEs, the resulting model is often called FEM/DEM [13-16]. In the field of masonry structures, this code has already been used for determining ultimate loads of masonry panels and arches [17,18]. Moreover, similar FEM/DEM codes have been recently introduced and applied to the field of masonry structures in-plane loaded by static and dynamic actions $[19,20]$. Thanks to the FE discretization, FEM/DEM codes are able to simulate masonry damage both at joint level and at block level; however, the number of degrees of freedom involved in analysis requires a large computational effort and for this reason it does not allow to model complex masonry structures.

In order to reduce the computational effort, discrete models with infinitely rigid elements may represent a simpler modelling choice, in particular if ancient masonry characterized by strong blocks and weak mortar or dry joints is studied. It must be pointed out that masonry specimens may be characterized by a regular arrangement of resisting elements having a well-defined square or rectangular shape; moreover, displacements caused by any type of load are usually smaller than those that may be found in soil and rock systems. In particular, contact topology does not vary during analysis, due to the small displacements with respect to the overall specimen dimensions. For these reasons, a simplified discrete model that neglects contact detection algorithms allows to further reduce the computational effort of the analysis. Cecchi and Sab [21] proposed a simple and effective discrete model with rigid elements and elastic interfaces for modelling regular masonry inand out-of-plane loaded. This model was extended to the case of random masonry [22] and recently it has been extended to the in-plane modal analysis of regular masonry by introducing a matrix solution method [23]. In particular, the rigid DEM has been recently extended to the nonlinear analysis of in-plane loaded masonry panels by adopting a Mohr-Coulomb yield criterion for restraining joint actions [24]. A model adopting the same assumptions in linear and non-linear fields was studied by Trovalusci and Masiani [25], moreover it is worth noting that the hypotheses of rigid blocks and dry joints following a Mohr-Coulomb yield criterion are often adopted in the field of limit analysis of masonry [26-29].

The rigid DEM introduced previously has been already compared and calibrated with a FEM/DEM code in elasticity [30]. Moreover in a recent contribution, authors have initially compared the two models also accounting for material nonlinearity [31]. In this contribution, rigid DEM and FEM/DEM already considered by authors are deeply calibrated and compared in the field of material nonlinearity by performing a wide set of incremental analyses of masonry panels having dry and mortar joints. Such a comparison is fundamental for calibrating the joint stiffness values adopted by the rigid DEM with respect to the zero-thickness interfaces adopted by the FEM/DEM. Numerical analyses allow to determine ultimate loads and collapse mechanisms of the case studies 
considered; furthermore, the influence of panel overall dimension ratio is taken into account together with the influence of block dimension ratio. Ultimate loads are also compared with analytic solutions based on a homogenized yield criterion that takes into account masonry microstructure. This paper is organized as follows: the geometric model representing regular masonry is introduced and nonlinear behaviour at joint level is described; DEM and FEM/DEM are presented separately for first and then a parameter calibration between models is proposed; several case studies of masonry panels with varying overall dimension ratio and block dimension ratio are introduced; a homogenized yield criterion for masonry panels is defined and finally numerical tests with DEM and FEM/DEM are performed.

\section{GEOMETRIC AND MECHANIC MODEL}

Masonry panels having regular texture and subject to in-plane loads are investigated. Block dimensions are (Figure 1a): $a$ (height), $b$ (width) and $t$ (thickness). Masonry regularity is represented by the so-called 'running bond' pattern, characterized by each block surrounded by six neighbours by means of six interfaces (Figure 1b). Due to the pattern considered, horizontal interfaces width is equal to half block width and vertical interfaces height is coincident with block height. In the following, four block width-to-height ratios are taken into account in order to evaluate the influence of local size effect on overall panel behaviour with particular attention to ultimate loads and collapse mechanisms, for instance $b / a=4,2,1,0.25$ (Figure 2). Following the hypotheses adopted by authors in previous contributions [21-24,31], blocks are modelled as rigid bodies, dry or weak/thin mortar joints are modelled as interfaces and plane stress hypotheses are adopted. Then, block displacement is described by a rigid body motion, characterized by in-plane block center translation $\mathbf{u}^{i, j}=\left\{u_{1}^{i, j} u_{2}^{i, j}\right\}^{T}$ and by a rotation with respect block centre $\omega_{3}^{i, j}$, having $i, j$ denoting block order, where $j$ can assume any integer value and $i$ is such as $i+j$ is always even.

The deformability of the model is lumped at interface level. Interfaces between blocks are modelled following an elastoplastic constitutive law, based on a Mohr-Coulomb yield criterion. In the elastic field [32], the interface behaviour is given by a linear relation between interface tractions and deformations between adjacent blocks. Then, normal and tangential stresses $\boldsymbol{\sigma}=\left\{\sigma_{\perp} \sigma_{\|}\right\}^{T}$ over a generic interface depend on the relative displacements [[d] $]=\left\{\begin{array}{lll}d_{\perp} & d_{\|} & d_{3}\end{array}\right\}^{T}$ between the blocks connected by the interface: $\boldsymbol{\sigma n}=\mathbf{K}[[\mathbf{d}]]$, where $\mathbf{n}$ is the vector normal to the interface. In case of mortar joints, the interface stiffness matrix $\mathbf{K}$ depends on the Young's modulus $E^{M}$ and the Poisson's ratio $v^{M}$ of mortar [21], whereas in case of dry joints, a fictitious stiffness is defined, accounting for block surface roughness. 
Material nonlinearity is considered at interface level only, due to the hypothesis of rigid blocks. Mortar or dry joints are modelled as a Mohr-Coulomb interfaces, then the yield criterion depends on cohesion $c \geq 0$ (with $c=0$ in case of dry joints) and friction angle $0<\phi<\pi / 2$. Adopting a statically admissible approach, the failure condition over a generic interface $\Sigma$ can be expressed as $f\left(\sigma_{\perp}, \sigma_{\|}\right)=\left|\sigma_{\|}\right|+\sigma_{\perp} \tan \phi-c \leq 0$.

Adopting a cinematically admissible approach, for any point along the interface, the Mohr-Coulomb yield criterion is expressed by

$$
\pi(\mathbf{n},[[\dot{\mathbf{u}}]])=\left\{\begin{array}{cc}
c \cdot \operatorname{ctg} \phi[[\dot{\mathbf{u}}]] \cdot \mathbf{n} & \text { if }[[\dot{\mathbf{u}}]] \cdot \mathbf{n} \geq|[[\dot{\mathbf{u}}]]| \sin \phi \\
+\infty & \text { otherwise }
\end{array}\right.
$$

where $[[\dot{\mathbf{u}}]]$ denotes the velocity jump across the interface $\Sigma$ when following the normal $\mathbf{n}$ to the $\Sigma$ interface. The first case may be also expressed as $u_{\perp} \geq u_{\|} \cdot \tan \phi$.

\section{DISCRETE MODEL WITH RIGID ELEMENTS}

The rigid discrete element model (DEM) reviewed here is based on the original numerical method formulated in elastic field in case of regular periodic masonry [21], and recently extended to the field of material nonlinearity [24]. Particularity of the proposed model is the reduction of its degrees of freedom to block centre translations and block rotation with respect to its centre: $\mathbf{q}^{i, j}=\left\{u_{1}^{i, j}, u_{2}^{i, j}, \omega_{3}^{i, j}\right\}^{T}$ (Figure 1b). Then, panel overall degrees of freedom are collected in $\mathbf{q}$ and relative displacements between adjacent blocks connected by an interface may be written as function of block degrees of freedom by means of a 'compatibility matrix' [24] that is frequently adopted for performing limit analysis [28,29]. The discrete model is also able to integrate interface stresses to a set normal and tangential forces and a couple, $\mathbf{f}=\left\{\begin{array}{lll}f_{\perp} & f_{\|} & m_{3}\end{array}\right\}^{T}$, applied to block centres and in equilibrium with external forces (Figure 3). In the elastic case, it can be demonstrated that $\mathbf{f}=\overline{\mathbf{K}}[[\mathbf{d}]]=\mathbf{K} \mathbf{A}[[\mathbf{d}]]$, where $\mathbf{A}$ is a diagonal matrix collecting interface area and moment of inertia [23,24], [[d] ] $=\left\{\begin{array}{lll}d_{\perp} & d_{\|} & d_{3}\end{array}\right\}^{T}$, and the diagonal terms of tensor $\overline{\mathbf{K}}$ are $K_{\perp}, K_{\|}$, and $K_{m}$, representing normal, tangential and rotational interface stiffnesses, respectively. In the non-linear field, interface actions must satisfy the Mohr-Coulomb yield criterion, represented by the following conditions [24,25]:

$f_{\perp}=\mathbf{f} \cdot \mathbf{e}_{\perp} \leq f_{t}$,

$\left|f_{\|}\right|=\left|\mathbf{f} \cdot \mathbf{e}_{\|}\right| \leq\left(f_{t}-f_{\perp}\right) \tan \phi$,

$\left|m_{3}\right| \leq\left(f_{t}-f_{\perp}\right) l_{c}$. 
that represent, respectively, detachment, sliding and rotational failure modes, where $f_{t}=c S / \tan \phi$ is the tensile strength of the interface, with $S=S_{v}=a t$ or $S_{h}=b t / 2$ for a vertical and horizontal interface, respectively. Characteristic interface length $l_{c}$ is the maximum distance of the interface normal force with respect to block centre. Authors already showed that static problems of masonry panels subject to external actions may be solved by means of a molecular dynamics algorithm $[21,33,34]$, that solves the equation of motion for each block degree of freedom and then applies the restrictions of Eq. 3 to interface actions. Another solution choice is a static solution algorithm, that requires to determine and to update panel stiffness matrix by setting equal to zero local interface stiffness values if the corresponding conditions in Eq. 3 are not respected. The latter method turned out to be faster than the first one for performing pushover analyses [24].

\section{FEM/DEM MODEL}

In recent times an increasing number of models attempted to combine the advantages of Finite and Discrete Element methods. In the late 1980's, Cundall [35] and Hart, Cundall and Lemos [36] proposed a model with deformable blocks discretized by an internal Finite Element mesh with 2D triangular plane strain elements. Shi and Goodman [12] developed a discontinous deformation analysis method where deformable blocks are assumed to be in a state of uniform strain and stress. Barbosa [37] proposed a Discrete-Finite Element model where deformable blocks are meshed by quadrilateral isoparametric Finite Element.

One of the approaches that combines DEM and FEM is the combined Finite-Discrete Element method (FEM/DEM) developed by Munjiza in the early 1990's [13,14]. It consists in a discrete element method in which the individual elements are meshed into finite elements. The model relies into a triangular discretization of the domain with embedded crack elements that activate whenever the peak strength is reached. Finite elements allow for the reproduction of elastic strain into continuum, while discrete element algorithms allows to model interaction, fracture and fragmentation processes.

Differently from the DEM described above, blocks can be assumed to behave as elastic bodies. Mortar joints might be idealized as elastic or elastic-plastic zero-thickness Mohr-Coulomb interfaces. In the present case, blocks have been modelled by means of finite elements while interfaces are modelled as discrete elements.

These models, initially developed in the field of geo-mechanics, can properly represent the behaviour of historical masonry, which could be considered as made of dry stone blocks exhibiting a periodic pattern. FEM/DEM allows to further extend the study to both linear and nonlinear 
masonry behaviour, it has been successfully adopted to study the behaviour of historical masonry construction [17-19,30,31,38].

The analyses have been performed by means of the FEM/DEM Y2D code [14], in particular the updated version Y-GUI [15] to make the input file and the Y-Geo code developed by the Geo Group of the Toronto University [16] to run the analyses, under 2D plane stress conditions.

Joints are modelled as elastic-plastic Mohr-Coulomb interfaces, by means of specific cracks elements that are embedded between all the Finite Elements of the mesh. The mechanical parameters adopted for the joints are: cohesion $c$, friction angle $\phi$ and tensile strength $\sigma_{t}$ which is set equal to $c / \tan \phi$.

Fracture energy defines the non-linear behaviour of the cracks elements once the value of cohesion or tensile strength - depending by the kinematic mechanism activated - are reached. Two different fracture energies are adopted: fracture energy of first mode $G I_{C}$, related to the de-cohesion mechanism, and fracture energy of second mode $G I I_{C}$, related to slippage mechanism. Fracture energy has been calculated as [39]:

$$
\begin{aligned}
& G I_{C}=\frac{l \cdot \pi \cdot c^{2}}{E^{M}} \\
& G I I_{C}=\frac{l \cdot \pi \cdot t_{S}{ }^{2}}{E^{M}}
\end{aligned}
$$

Where $l$ is the length of interface, equal to $b$ for a horizontal one and to $a$ for a vertical one, and $E^{M}$ is the Young's modulus of the joints. In the model, the joints are modelled as zero-thickness interfaces, therefore the young's modulus $E^{M}$ adopted is a Young's modulus suitable for mortar.

\section{FEM/DEM AND DEM PROCEDURES}

DEM and FEM/DEM are characterized by several differences related to the parameters needed for describing masonry linear and nonlinear behaviour, together with different solution strategies for obtaining incremental curves for masonry panels subject to dead and live increasing loads.

Considering masonry elements, DEM is characterized by infinitely rigid blocks, hence no parameters are needed for their description, whereas FEM/DEM envisages the definition of block elastic modulus and Poisson ratio $E^{B}, v^{B}$ and a FE discretization of each block is adopted by means of constant strain triangular elements, as showed by Figure 4a for the four different texture types considered in this work. In order to compare the two models, blocks are considered rigid in FEM/DEM by the adoption of a very high value of $E^{B}(1000 \mathrm{GPa})$ and assuming $v^{B}=0$.

Considering then joints or contacts between elements, DEM joints are represented by relative actions -normal force, shear force and moment- between the centres of adjacent blocks, depending 
on block relative displacements. DEM interface elastic behaviour is governed by interface stiffness values, that depend on mortar elastic parameters $E^{M}, v^{M}$; whereas nonlinear behaviour follows a simple Mohr-Coulomb yield criterion (Eq. 3). In FEM/DEM, joints are modelled by specific zerothickness four-noded interface elements, that are embedded between the edges of all adjacent triangular element pairs since from the beginning of simulation [40]. Then, potential cracks can open both between block elements and both along interfaces between blocks. In order to simulate historic masonry behaviour, with cracks usually occurring along mortar or dry joints [3,41], two different interface elements have been used: an elastic one inside the block FEs for avoiding block cracking, and an elastoplastic one between adjacent blocks, following the Mohr-Coulomb yield criterion (Eq. 1). The Mohr-Coulomb parameters adopted for DEM interfaces are also adopted for FEM/DEM joint parameters, in particular cohesion $c$, friction ratio $\tan \phi$, tensile strength $\sigma_{t}=$ $c / \tan \phi$; whereas and fracture energy (Eqs. 4 and 5 ) is evaluated by assuming the same $E^{M}$ adopted by DEM.

The rigid DEM adopted in this work is based on small displacement hypothesis. In particular, block centre positions are not updated during analysis accounting for increasing displacements and no contact detection algorithms are needed, given that texture regularity is maintained during analyses. On the other hand, FEM/DEM is based on finite displacements, therefore larger displacements may be reached during non-linear behaviour with respect to DEM.

Focusing then on solution strategies, in this work, analyses performed with DEM adopt a static solution method, that allows performing fast pushover analyses with a small computational effort with respect to a molecular dynamics solution method [24]. FEM/DEM, instead, is based on a molecular dynamics solution method, which implies a wider computational effort respect to the static solution method adopted by DEM but that does not require the definition of the stiffness matrix of the entire masonry assemblage. Contact between discrete elements together with the deformability of discrete elements is described in terms of nodal forces and nodal displacements. The governing dynamic equations of the problem are solved adopting the central difference time integration scheme, that is an explicit integration scheme of the equation for each degree of freedom. With respect to the solution adopted by DEM, here it is not necessary to assemble or store stiffness matrices. The stability of the scheme is achieved through reducing the time step size, resulting in an increasing of computational effort for more refined mesh. Moreover, the following incremental analyses performed by FEM/DEM are obtained as the results of several dynamic nonlinear analyses performed for each increasing value of incremental load As previously stated, in the DEM, thanks to rigid block hypothesis, forces are applied at block centres (Figure 4b) and, similarly, panel restraints are imposed at block centres, whereas in the 
FEM/DEM, forces are lumped at the inner nodes of each block subdivision (Figure 4a). Different

block subdivision are adopted in FEM/DEM depending by the arrangement of blocks, in order to allows the definition of different joints inside or between the blocks.

\section{NUMERICAL TESTS}

In the following numerical tests, two loading conditions are taken into account:

i) panel subject to self-weight and increasing lateral loads, with varying slenderness and block dimensions and supported along its base;

ii) square panel subject to a symmetric vertical concentrated load, and supported at base edges, with varying block dimensions.

\subsection{Panel subject to self-weight and increasing lateral loads}

\subsubsection{Geometric and mechanic parameters}

Three different base supported panels are considered, together with four block width-to-height ratios, as stated in the first paragraph. Panel width $L$ is assumed constant and equal to $1440 \mathrm{~mm}$, whereas height $H$ is assumed equal to $L / 2, L$ and $2 L$ (Figure 5). Blocks arranged in a 'running bond' pattern, with $b=240 \mathrm{~mm}$ and $a=60 \mathrm{~mm}$ (then, $b / a=4$ ), are assumed as reference case. Table 1 resumes panel dimensions, block dimensions and block number in both plane directions ( $n_{1}$ and $n_{2}$, respectively) for the case studies considered. It is worth noting that block and panel thickness $t=$ $120 \mathrm{~mm}$ is assumed to be constant. Negligible cohesion $c$ is considered for representing dry joints, whereas a friction ratio $\tan \phi=0.6$ is assumed, corresponding to a friction angle of about $30^{\circ}$. A fictitious mortar elastic modulus $E^{M}=1 \mathrm{GPa}$ is assumed for representing dry joints elastic deformability. Each panel is subject to a uniform vertical load representing its self-weight and to a horizontal increasing force representing a lateral acceleration statically applied. Then, nonlinear incremental analyses of the panels considered are performed in order to determine their ultimate load multiplier ( $\lambda_{\text {DEM }}$ and $\left.\lambda_{\text {FEM/DEM }}\right)$ and the corresponding collapse mechanisms.

\subsubsection{Incremental analyses}

Ultimate load multipliers obtained with DEM and FEM/DEM are collected in Table 2, together with the corresponding analytic solutions obtained with a homogeneous material equivalent to masonry in its geometry and in the material properties [42]. In particular, in case of shear failure, the collapse multiplier is $\lambda_{\text {номо }}=\tan \phi$, whereas in the case of flexural failure, a rigid body rotation mechanism is activated by a cracking line having inclination $\psi$ from the lower-right corner of the panel, $\tan \psi \leq(m / \tan \phi)^{-1 / 2}$, with $m=2 a / b$, and the collapse multiplier is given by: 
$\lambda_{\text {номо }}=\left\{\begin{array}{cc}\frac{1}{2}(m / \tan \phi)^{-1 / 2} & \text { if } r=H / L \leq(m / \tan \phi)^{1 / 2} \\ \frac{3 r-2(m / \tan \phi)^{-1 / 2}}{3 r^{2}-(m / \tan \phi)} & \text { otherwise }\end{array}\right.$

Further details may be found in the works of De Buhan and De Felice, Cecchi and Vanin [43,44],

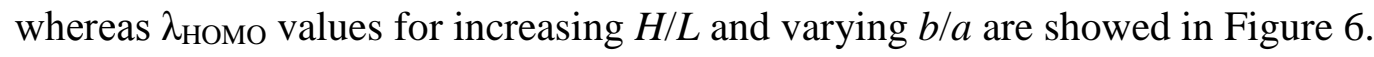

Figure 7 collects incremental curves obtained with the numerical models, compared with analytic solutions and Figures 8-10 collect collapse mechanisms.

- Thick panel $(H / L=0.5$, Figure 8$)$ : DEM collapse mechanisms are characterized by a slight sliding of horizontal joints that increases along panel height and by the rotation of blocks close to the upper-right corner for $b / a$ from 4 to 1 . The case with $b / a=1 / 4$ is characterized by a generalized block rotation along second and third rows. FEM/DEM collapse mechanisms present a more evident sliding of horizontal joints with respect to block rotation. Such differences in collapse mechanisms are motivated by the joint rotational stiffness accounted by DEM that allows a more evident block rotation with respect to the FEM/DEM. However, ultimate loads obtained with the two numerical models are in quite good agreement also with analytical results for $b / a$ from 4 to 1 . For the case with $b / a=1 / 4, \mathrm{FEM} / \mathrm{DEM}$ is characterized by an ultimate load multiplier closer to that obtained with $b / a=1$, probably due to the same size of horizontal interfaces that govern the sliding mechanism (Eqs. 4 and 5).

- Square panel $(H / L=1$, Figure 9): collapse mechanisms obtained with DEM and FEM/DEM are typical shear failure mechanisms, characterized by a diagonal cracking line starting from the lowerright corner and moving to the upper portion of panel left side. The resulting triangular/trapezoidal panel portion over the cracking line is subject to a rotation or overturning mechanism. Due to the rigid block hypothesis, cracking line involves subsequent horizontal and vertical dry joints, however its overall inclination increases for reducing $b / a$ ratio, as showed also by the analytic solution $\left(\tan \psi \leq(m / \tan \phi)^{-1 / 2}\right)$. This aspect is evident for the panel with $b / a=1 / 4$, that is characterized by a small triangular portion collapsing on the right side of the panel. Moreover, FEM/DEM collapse mechanism shows a clear crack line with an overall inclination equal to $45^{\circ}$, given that horizontal joint length is coincident with vertical joint height. In this case, DEM and FEM/DEM collapse load multipliers are in better agreement with respect to the previous case for all b/a ratios considered. Moreover, both numerical models are in quite good agreement with analytic solutions, except for the case with $b / a=4$.

- Slender panel $(H / L=2$, Figure 10): collapse mechanisms obtained with DEM and FEM/DEM are characterized by a diagonal crack similarly to the previous case. However in this case, a bigger and 
slender portion of the panel is subject to a rotation mechanism, leading to smaller collapse load multipliers with respect to the other panels considered. The slender panel with $b / a=1 / 4$ is characterized by a small triangular portion subject to an overturning mechanism. More generally, with this panel type, collapse load multipliers are in quite good agreement with analytic solutions.

\subsection{Panel subject to a vertical concentrated force}

\subsubsection{Geometric and mechanic parameters}

Here, analyses are limited to the square panels studied in the previous sub-paragraph (cases 2, 5, 8 and 11 in Table 1). Panels are simply supported at the lower corners, whereas the concentrated load $P$ is applied at the upper edge midpoint This condition is quite similar to the deep beam test performed by Page [2]. In order to avoid sudden collapse mechanisms along the lower edge, a notnegligible interface cohesion $c=0.1 \mathrm{MPa}$ is adopted, whereas $\tan \phi=0.6$ is assumed equal to the previous case studies, together with $E^{M}=1 \mathrm{GPa}$.

\subsubsection{Incremental analyses}

Figure 11 collects incremental curves obtained with DEM and FEM/DEM for the four square panels, with vertical displacement evaluated at the upper edge midpoint. Figure 12 collects the corresponding collapse mechanisms. The numerical models adopted are in quite good agreement both for this case study, even if FEM/DEM turns out to be slightly stronger and less deformable than DEM. Ultimate loads and collapse mechanisms are strictly depending on blocks engagement given by block height-to-width ratio. For this reason, the panel with $b / a=4$, characterized by the best engagement, has a collapse load larger than those obtained with other $b / a$ ratios. More generally, collapse loads decrease as a consequence of the smaller block engagement and the collapse mechanisms are characterized by diagonal cracks starting from base supports and moving towards panel vertical axis of symmetry. The restraint condition chosen is able to show an 'arch mechanism' that is typical of masonry façade spandrels over openings, subject to the collapse or to an excessive vertical displacement of the lintel. The portion of masonry panel involved in such a mechanism is characterized by a triangular or trapezoidal shape which dimensions increase for decreasing block engagement.

\section{CONCLUSIONS}

In this contribution, the nonlinear behaviour of masonry panels with regular texture and subject to in-plane loads has been investigated by means of two numerical models: a Discrete Model (DEM) developed by authors and a Discrete/Finite Element Model (FEM/DEM) originally introduced for 
studying rock mechanics problems and effectively extended to masonry structures. These models have been compared and calibrated, given that a Mohr-Coulomb yield criterion have been adopted for representing joint or interface elastic-plastic behaviour in both numerical models. Moreover, rigid block hypothesis typical of the proposed DEM has been also considered with FEM/DEM by adopting a large elastic modulus for blocks.

Numerical pushover analysis of masonry panels subject to self-weight and increasing proportional lateral loads have been performed for first and an analytical homogenized model has been taken as reference for the determination of collapse load multipliers. Three different panel height-to-width ratios and four different masonry textures have been considered. Then, focusing on the square panel, a second case study has been considered for simulating a mechanism typical of masonry spandrels with a weak or damaged supporting lintel.

The numerical test campaign showed that the DEM and FEM/DEM models represent a simple and effective tool for studying the nonlinear behaviour of masonry structures, in particular both models are able to take into account the actual texture of masonry walls, thus they are able to describe with accuracy the real crack pattern that may develop in masonry walls and to reveal the potential collapse mechanisms. DEM is simpler than FEM/DEM and requires a smaller computational effort, however it is less accurate than FEM/DEM and it does not account for typical aspects of discrete models such as large displacements and contact variation during analysis. DEM turns out to be a good and fast modelling choice for studying historical masonry specimens characterized by weak or dry joints between blocks, whereas it is not able to represent block deformation and cracking in case of stronger mortar joints and in this last case the FEM/DEM represents the more accurate solution. However, the critical comparison and calibration between DEM and FEM/DEM carried out in this work allowed to obtain results in good agreement also with the analytic solution.

The sensitivity analysis to masonry geometric parameters in the first case study showed that sliding collapse mechanisms are typical of thick panels with larger horizontal joint length with respect to vertical joint height, these mechanisms are characterized by ultimate load multipliers quite close to the value of friction ratio. Rotation or overturning collapse mechanisms are typical of slender panels and of panels with smaller horizontal joint length with respect to vertical joint height.

The second case study showed the capability of both models to represent different collapse mechanisms governed by block dimensions in presence of a concentrated vertical force and supported base corners. Similarly to the first case study, the collapse loads decrease for decreasing blocks engagement.

Further developments of this work will regard the improvement of the current rigid DEM by adding inner interfaces into blocks, i.e. along block vertical axis of symmetry, in order to simulate the 
possible formation of vertical cracks along block height that are often found in masonry specimens with mortar joints and subject to both vertical and lateral loads. For this purpose, the FEM/DEM, that usually allows block cracking, will be fundamental for comparing results and calibrating DEM interface stiffness and strength parameters.

\section{COMPLIANCE TO ETHICAL STANDARDS}

Funding: The research has been carried out thanks to the financial support of PRIN 2015 (under grant 2015JW9NJT_014, project "Advanced mechanical modelling of new materials and structures for the solution of 2020 Horizon challenges"). The financial support of Università IUAV di Venezia, Department of Architecture, Construction, Conservation is also gratefully acknowledged.

Conflict of interests: The authors declare that they have no conflict of interest.

\section{REFERENCES}

[1] Lemos JV (2007) Discrete Element Modeling of Masonry Structures, Int J Archit Herit 1:190-213.

[2] Page AW (1978) Finite Element Model for Masonry. J Struct Div 104:1267-1285.

[3] Lourenço PB, Rots JG (1997) Multisurface interface model for analysis of masonry structures. J Eng Mech 123(7):660-668.

[4] Sulem J, Muhlhaus H (1997) Continuum model for periodic two-dimensional block structures. Mech of Cohesive-Frictional Mat 2(1):31-46.

[5] Masiani R, Trovalusci P (1996) Cosserat and Cauchy materials as continuum models of brick masonry. Meccanica 31(4):421-432.

[6] Addessi D, Sacco E, Paolone A (2010) Cosserat model for periodic masonry deduced by nonlinear homogenization. Eur J Mech A/Solids 29(4):724-737.

[7] Addessi D, Sacco E (2012) A multi-scale enriched model for the analysis of masonry panels, Int J Solids Struct 49:865-880.

[8] Addessi D, Sacco E (2016) Nonlinear analysis of masonry panels using a kinematic enriched plane state formulation. Int J Solids Struct 90:194-214.

[9] Cundall PA (1971) A computer model for simulating progressive large scale movements in blocky rock systems. Proceedings of Symposium of International Society of Rock Mechanics, Nancy, France, 1971.

[10] Cundall PA, Strack ODL (1979). Discrete Numerical Model For Granular Assemblies. Geotechnique 29(1):47-65.

[11] Itasca (1989) UDEC (Universal Distinct Element Code) Version ICG1.5 User's Manual. 
[12] Shi GH, Goodman RE (1988) Discontinuous deformation analysis - a new method for computing stress, strain and sliding of block systems. In: Key questions in rock mechanics, Rotterdam Balkema; 381-393.

[13] Munjiza A, Owen DRJ, Bicanic N (1995). A combined finite-discrete element method in transient dynamics of fracturing solids. Eng Comput 12(2):145-174.

[14] Munjiza A (2004) The finite/discrete element method, John Wiley and Sons, Chicester.

[15] Mahabadi OK, Grasselli G, Munjiza A. (2010) Y-GUI: A graphical user interface and preprocessor for the combined finite-discrete element code, Y2D, incorporating material inhomogeneity, Comput Geosci 36:241-252.

[16] Mahabadi OK, Lisjak A, Munjiza A, Grasselli G (2012) Y-Geo: a new combined finitediscrete element numerical code for geomechanical applications. Geomech 12:676-688.

[17] Reccia E, Cazzani A, Cecchi A (2012) FEM-DEM Modeling for Out-of-plane Loaded Masonry Panels: A Limit Analysis Approach, Open Civ Eng J 6(SPEC.ISS.1):231-238.

[18] Reccia E, Cecchi A, Milani G. (2016). A finite element-discrete element approach for the analysis of the Venice trans-lagoon railway bridge. Civil-Comp Proceedings, 110.

[19] Smoljanovic H, Zivaljic N, Nikolic Z (2013) A combined finite-discrete element analysis of dry stone masonry structures. Eng Struct 52:89-100.

[20] Smoljanović H, Nikolić Z, Živaljić N (2015). A combined finite-discrete numerical model for analysis of masonry structures. Eng Fract Mech 136:1-14.

[21] Cecchi A, Sab K (2004) A comparison between a 3D discrete model and two homogenized plate models for periodic elastic brickwork. Int J Solids Struct 41:2259-2276.

[22] Cecchi A, Sab K (2009) Discrete and continuous models for in plane loaded random elastic brickwork. Eur J Mech A/Solids 28:610-625.

[23] Baraldi D, Bullo S, Cecchi A (2016) Continuous and discrete strategies for the modal analysis of regular masonry. Int J Solids Struct 84:82-98.

[24] Baraldi D, Cecchi A (2016) Discrete approaches for the nonlinear analysis of in plane loaded masonry walls: Molecular dynamic and static algorithm solutions. Eur J Mech A/Solids 57:165-177.

[25] Trovalusci P, Masiani R (2003) Non-linear micropolar and classical continua for anisotropic discontinous materials. Int J Solids Struct 40(5):1281-1297.

[26] Livesley RK (1978) Limit analysis of structures formed from rigid blocks. Int J Numer Methods Eng 12(12):1853-1871.

[27] Gilbert M, Melbourne C (1994) Rigid-block analysis of masonry structures. Struct. Eng 72 (21):356-361. 
[28] Baggio C, Trovalusci P (1998) Limit analysis for no-tension and frictional threedimensional discrete systems. Mech Struct Mach 26(3):287-304.

[29] Ferris MC, Tin-Loi F (2001) Limit analysis of frictional block assemblies as a mathematical program with complementarity constraints. Int J Mech Sci 43:209-224.

[30] Baraldi D, Reccia E, Cazzani A, Cecchi A (2013) Comparative analysis of numerical discrete and finite element models: the case of in-plane loaded periodic brickwork. Compos Mech Comp Appl Int J 4:319-344, 2013.

[31] Baraldi D, Reccia E, Cecchi A (2015) DEM \& FEM/DEM models for laterally loaded masonry walls. COMPDYN 2015 - 5th ECCOMAS Thematic Conference on Computational Methods in Structural Dynamics and Earthquake Engineering, 2144-2157.

[32] Klarbring A (1991) Derivation of model of adhesively bounded joints by the asymptotic expansion method. Int J Eng Sci 29:493-512.

[33] Allen MP, Tildesley DJ (1994) Computer simulations of liquids. Oxford Science Publications.

[34] Owen DRJ, Hinton E (1980) Finite elements in plasticity: theory and practice. Pineridge Press Limited, Swansea U.K.

[35] Cundall PA (1988) Formulation of a three-dimensional distinct element model-part I. A scheme to detect and represent contacts in a system composed of many polyhedral blocks. Int $\mathrm{J}$ Rock Mech Mining Sci 25(3):107-116.

[36] Hart R, Cundall PA, Lemos J (1988) Formulation of a three-dimensional distinct element model-part II. mechanical calculations for motion and interaction of a system composed of many polyhedral blocks. International Journal of Rock Mechanics and Mining Sciences, 25(3), 117-125.

[37] Barbosa BE (1996) Discontinous structural analysis. In: Proceedings of the 11th world conference on earthquake engineering, 830 .

[38] Reccia E, Cecchi A, Milani G (2016) FEM/DEM Approach for the Analysis of Masonry Arch Bridges in: Sarhosis V, Bagi K, Lemos JV Milani G (ed) Computational Modeling of Masonry Structures Using the Discrete Element Method, IGI Global, doi: 10.4018/978-1-52250231-9.ch014

[39] Carpinteri A (1992) Meccanica dei materiali e della frattura. Pitagora Editrice, Bologna.

[40] Lisjak A, Liu Q, Zhao Q, Mahabadi OK, Grasselli G (2013) Numerical simulation of acoustic emission in brittle rocks by two-dimensional finite-discrete element analysis, Geophys J Int 195(1): 423-443.

[41] Luciano R, Sacco E (1997) Homogenization technique and damage model for old masonry material, Int J Solids Struct 34(24):3191-3208. 
[42] Anthoine A (1995) Derivation of the in-plane elastic characteristics of masonry through homogenization theory, Int J Solids Struct 32(2):137-163.

[43] De Buhan P, De Felice G (1997) A homogenization approach to the ultimate strength of brick masonry, J Mech Phys Solids 45(7):1085-1104.

[44] Cecchi A, Vanin A (2013) From micro to macro models for in plane loaded masonry walls: proposition of a multiscale approach. Compos Mech Comp Appl Int J 11(2):139-159. 


\section{FIGURE CAPTIONS}

Figure 1: Block dimensions (a) and geometric model adopted (b).

Figure 2: Block width-to-height ratios adopted in this work.

Figure 3: Interface between adjacent blocks and interface actions.

Figure 4: Detail of block representation and applied forces in case of FEM/DEM (a) and DEM (b).

Figure 5: Panels considered for the numerical tests.

Figure 6: Ultimate load multipliers for masonry panels subject to self-weight and increasing lateral loads, for increasing $H / L$ ratio and for four masonry patterns.

Figure 7: Incremental analyses for panels subject to self-weight and increasing lateral loads. Load multiplier vs. horizontal displacement at the upper-right corner of the panel. (a) $H / L=0.5$, (b) $H / L=$ 1 , (c) $H / L=2$.

Figure 8: Collapse mechanisms of masonry panels with $H / L=0.5$, subject to self-weight and increasing lateral loads.

Figure 9: Collapse mechanisms of masonry panels with $H / L=1$, subject to self-weight and increasing lateral loads.

Figure 10: Collapse mechanisms of masonry panels with $H / L=2$, subject to self-weight and increasing lateral loads.

Figure 11: Incremental analyses for square panels subject to an increasing vertical load at the upper edge midpoint. Load vs. vertical displacement.

Figure 12: Collapse mechanisms of square panels subject to an increasing vertical load at the upper edge midpoint.

\section{TABLE CAPTIONS}

Table 1: Case studies considered with the corresponding panel dimensions, block dimensions and block number along plane directions.

Table 2: Comparison between ultimate load multipliers for masonry panels subject to self-weight and increasing lateral loads. 


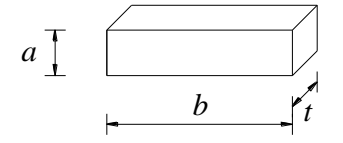

a

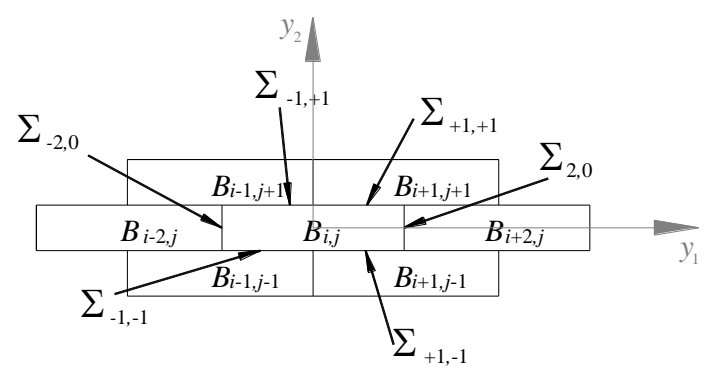

b

Figure 1: Block dimensions (a) and geometric model adopted (b). 


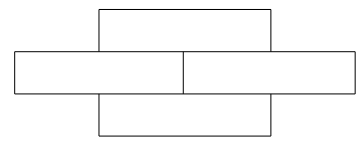

$b / a=4$

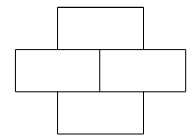

$b / a=2$

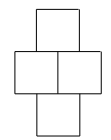

$b / a=1$



Figure 2: Block width-to-height ratios adopted in this work. 


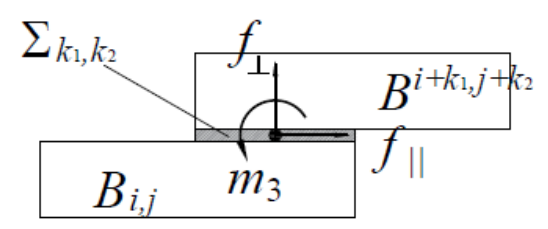

Figure 3: Interface between adjacent blocks and interface actions. 


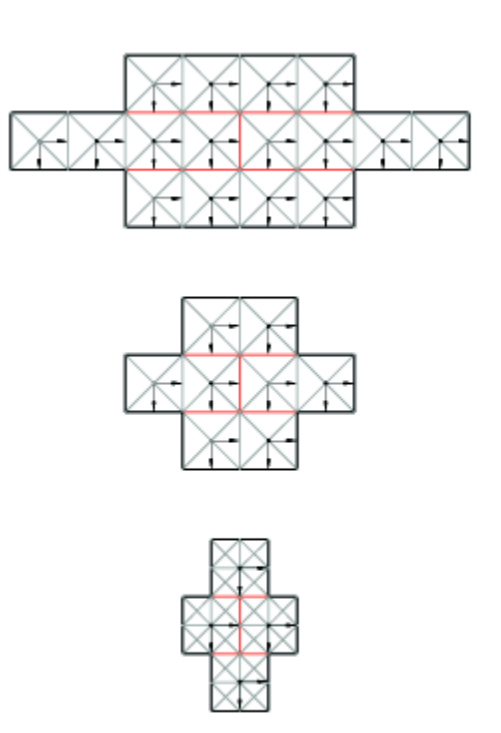

(a)

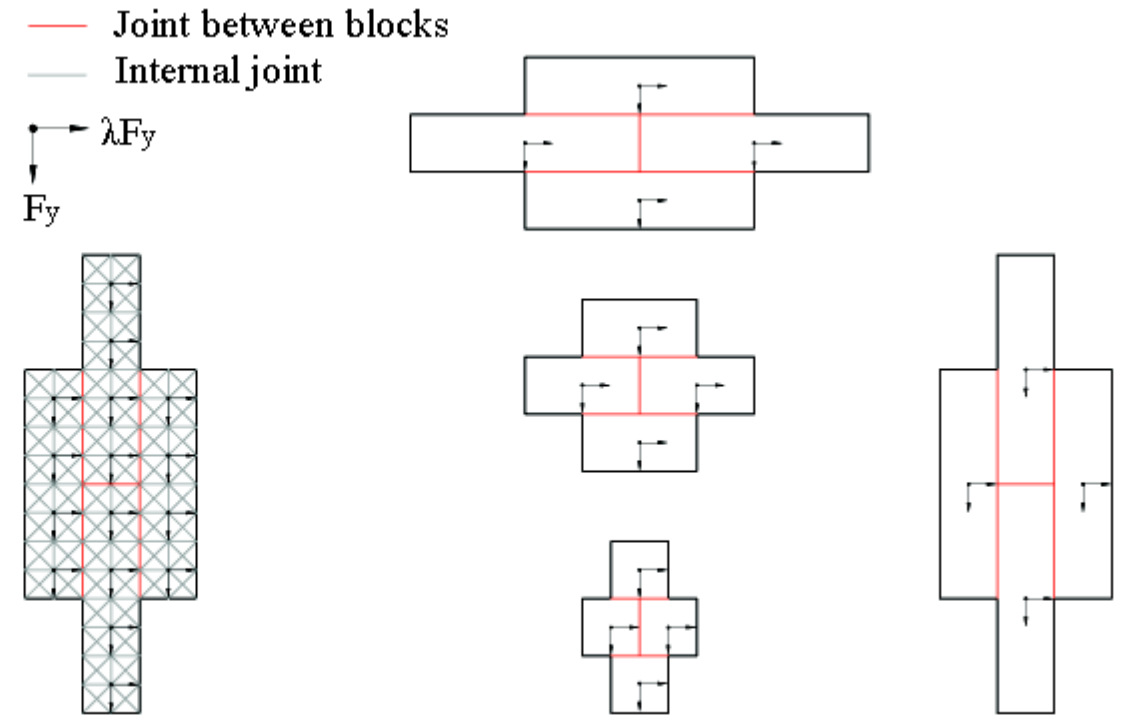

(b)

Figure 4: Detail of block representation and applied forces in case of FEM/DEM (a) and DEM (b). 


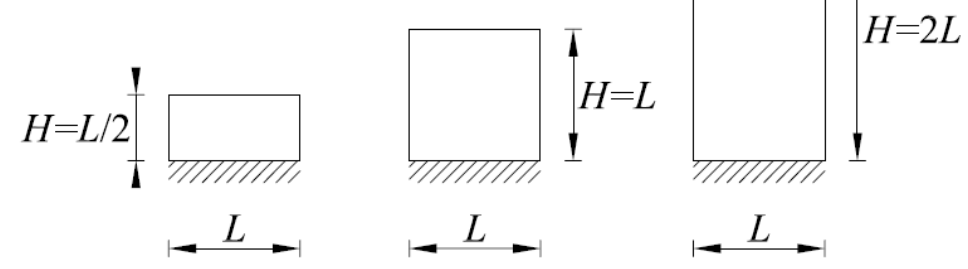

Figure 5: Panels considered for the numerical tests. 


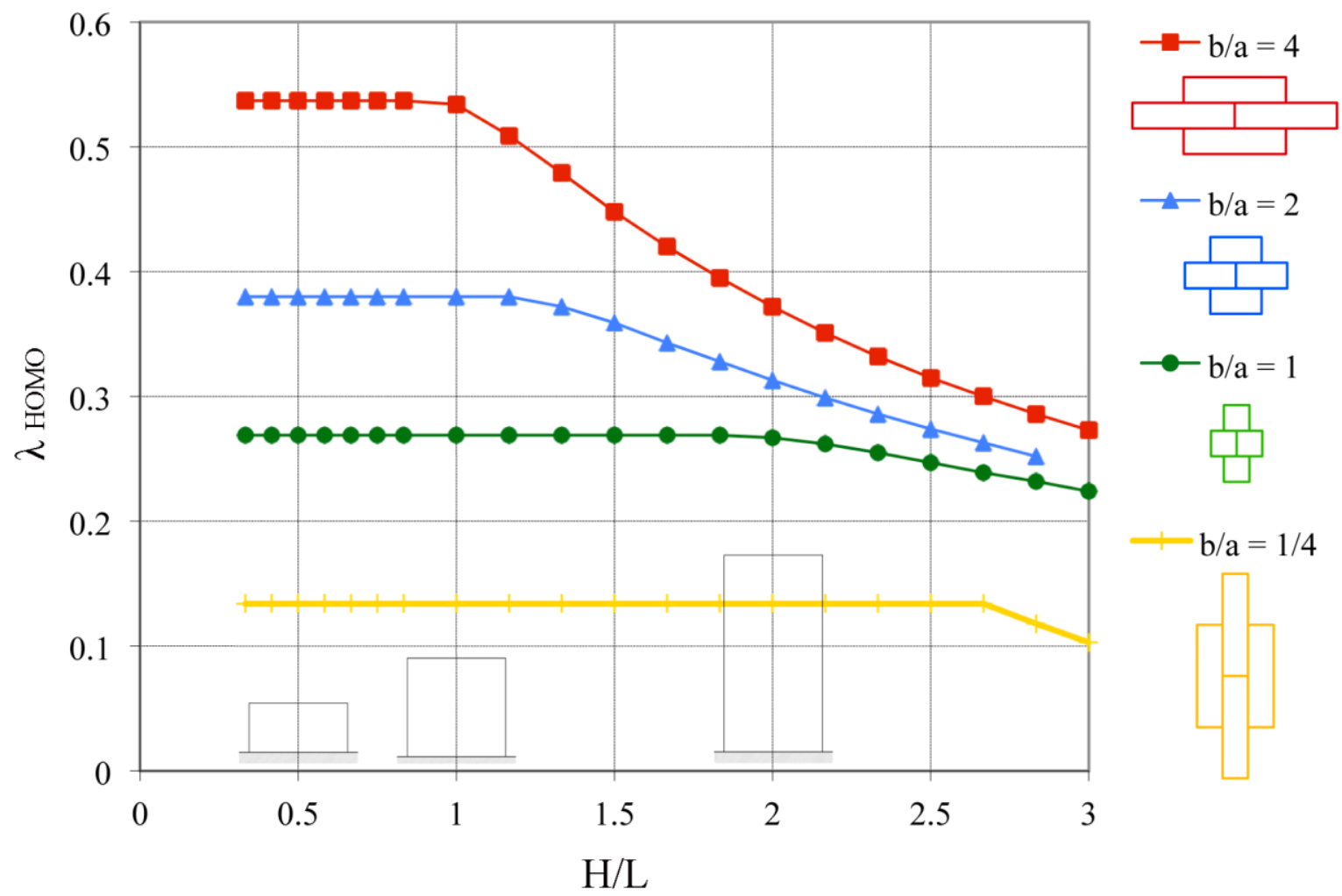

Figure 6: Ultimate load multipliers for masonry panels subject to self-weight and increasing lateral loads, for increasing $H / L$ ratio and for four masonry patterns. 

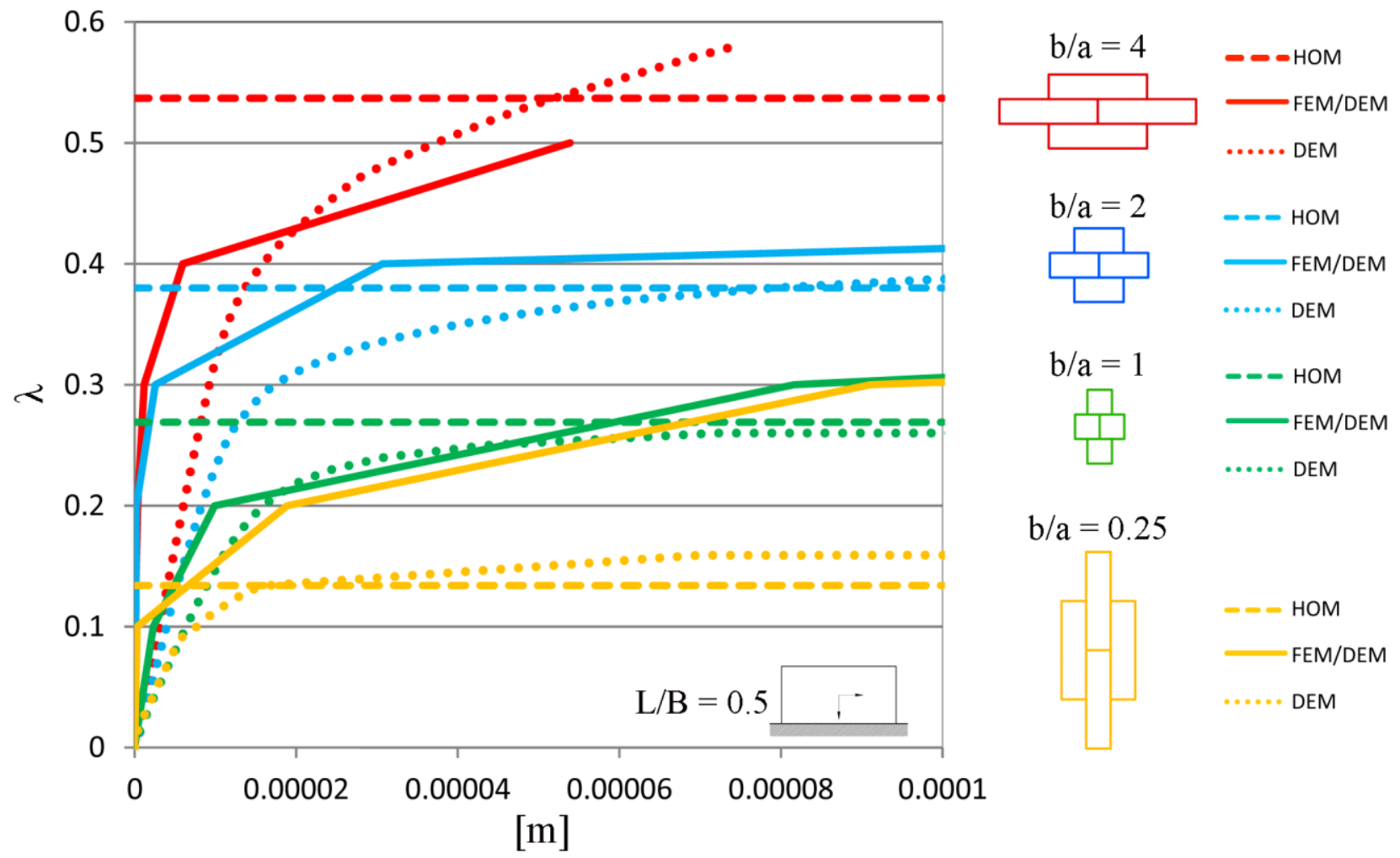

$\mathrm{b} / \mathrm{a}=0.25$

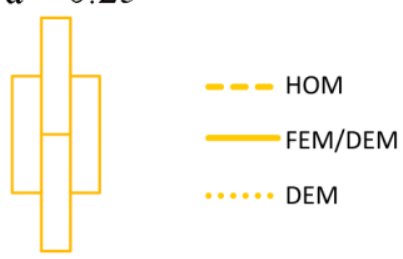

(a)

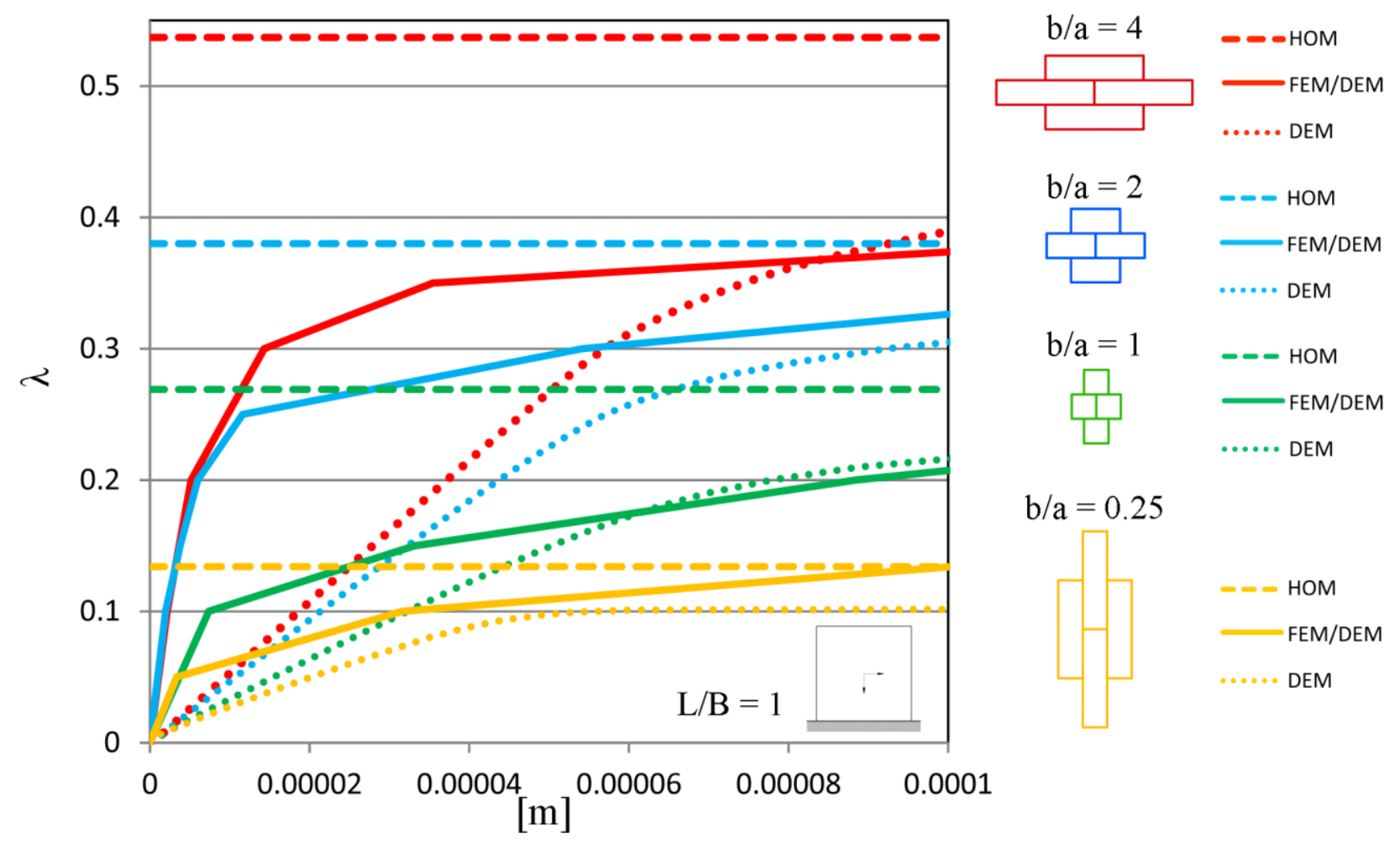

(b) 


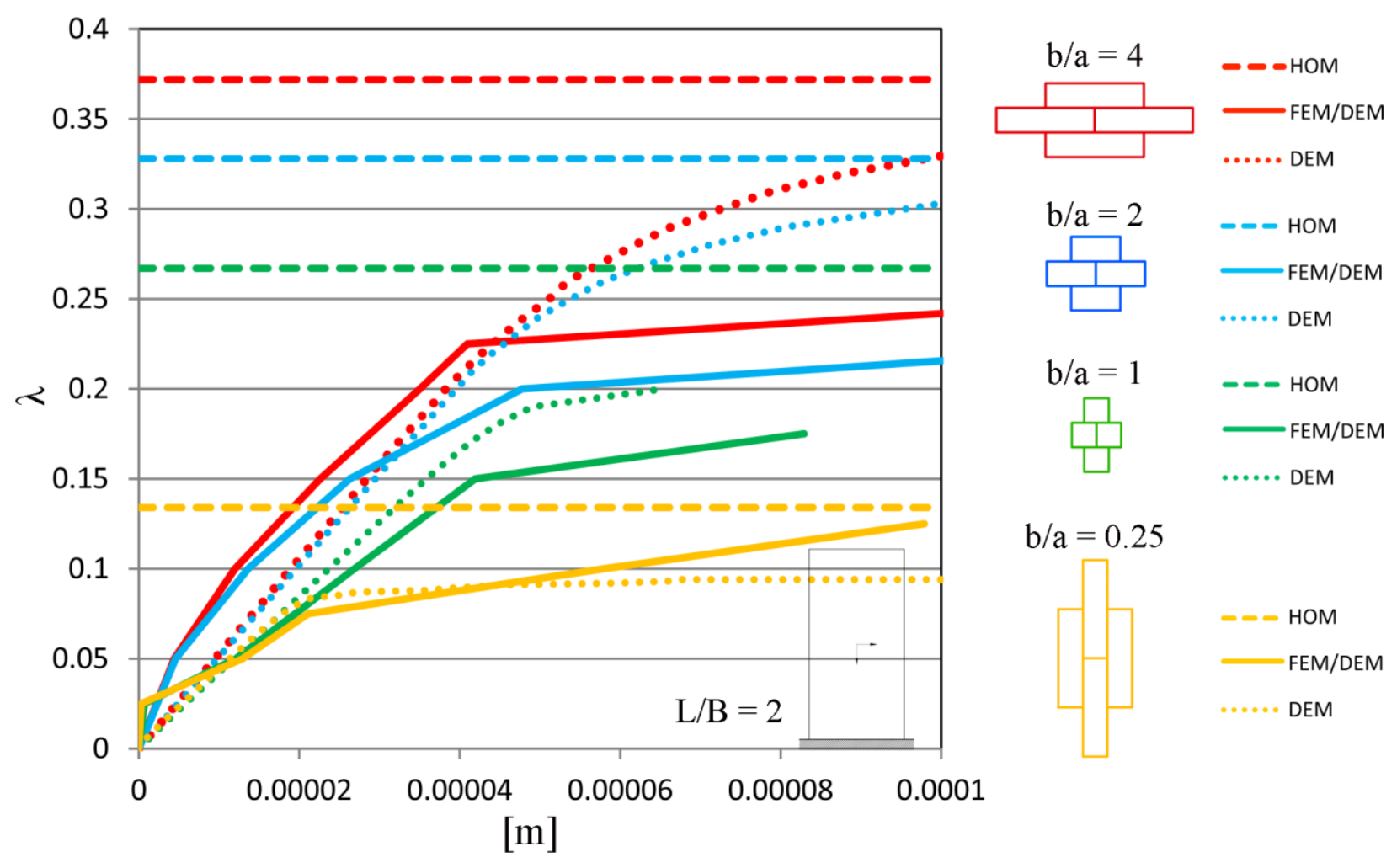

(c)

Figure 7: Incremental analyses for panels subject to self-weight and increasing lateral loads. Load multiplier vs. horizontal displacement at the upper-right corner of the panel. (a) $H / L=0.5$, (b) $H / L=$ 1, (c) $H / L=2$. 

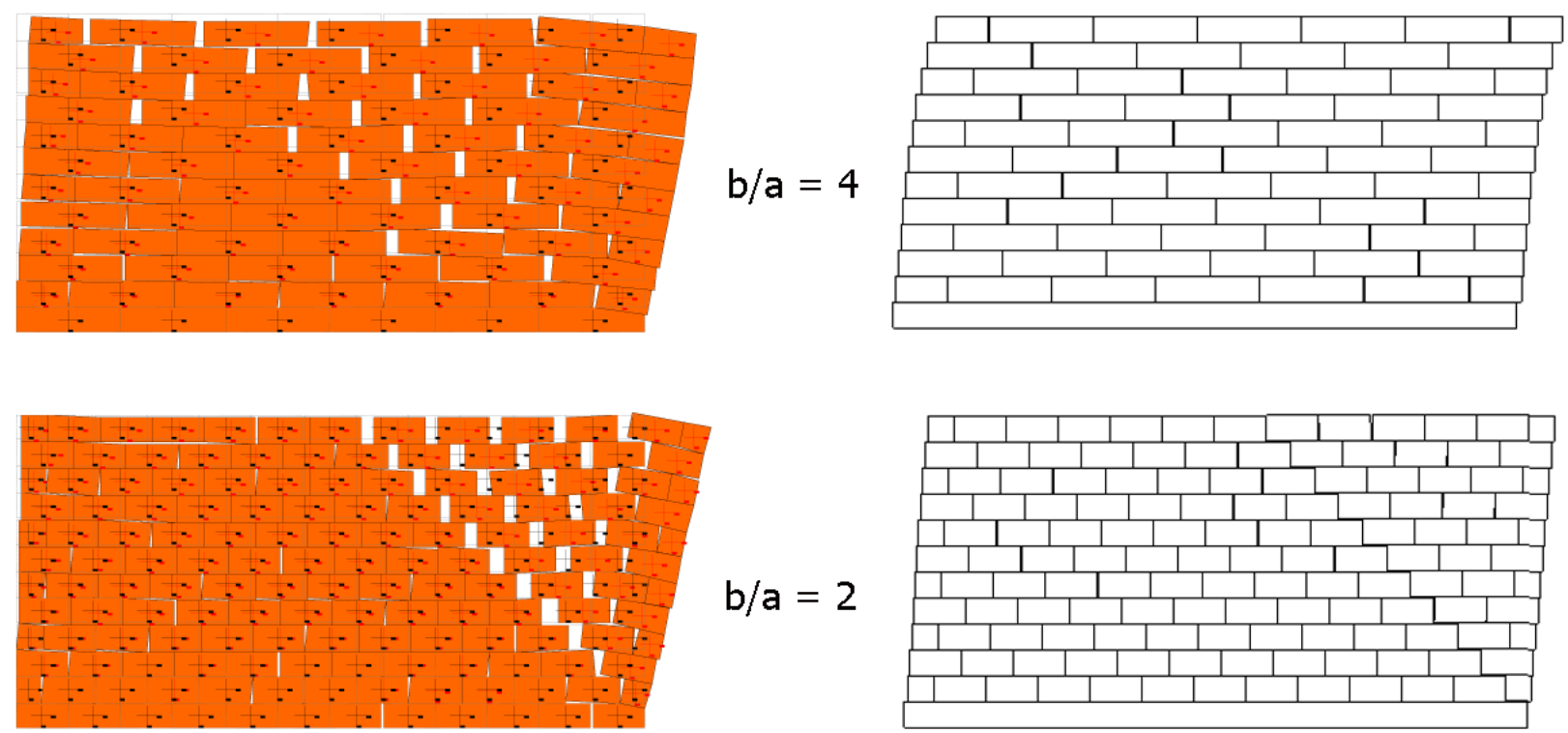

$\mathrm{b} / \mathrm{a}=2$
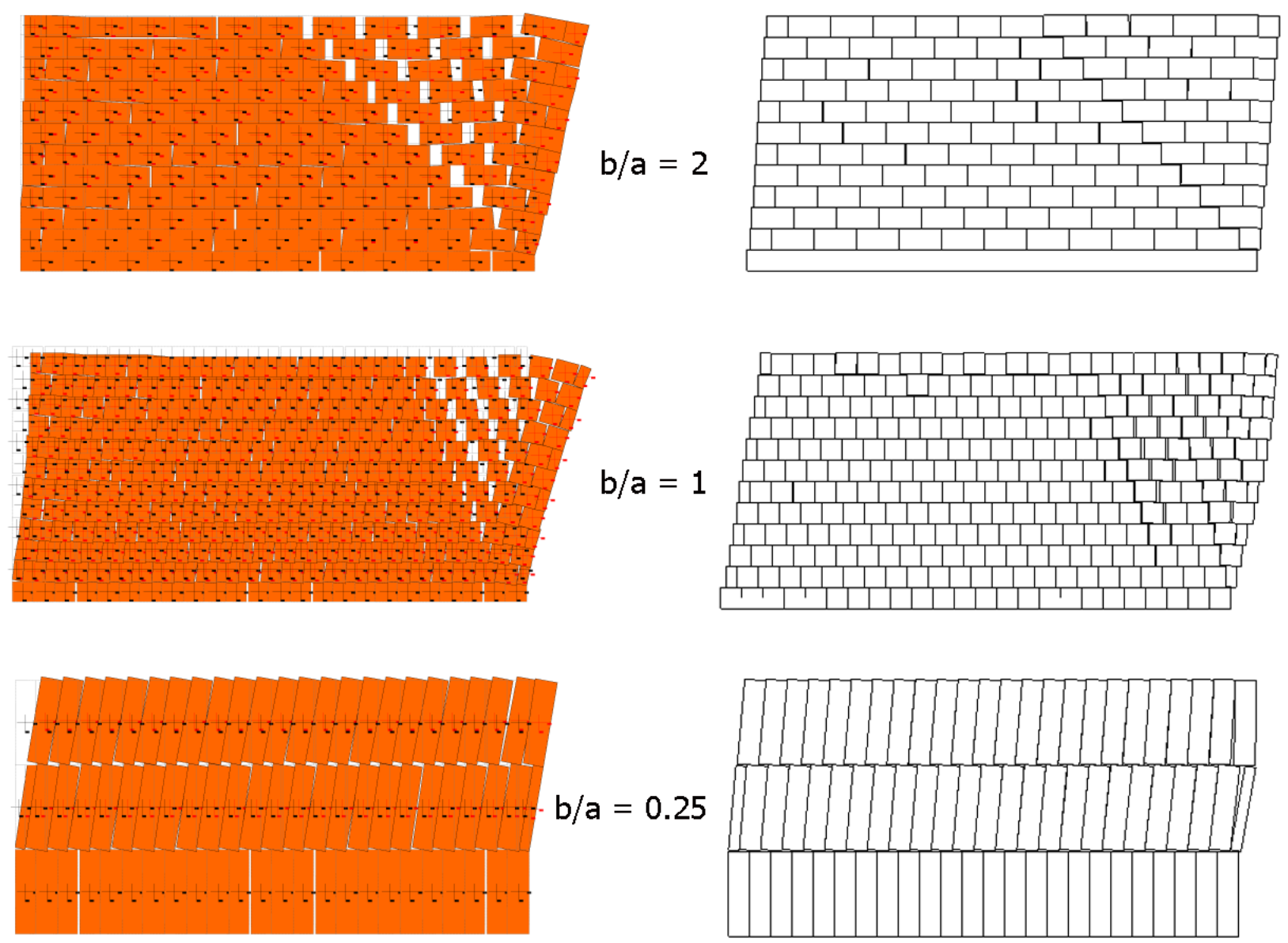

Figure 8: Collapse mechanisms of masonry panels with $H / L=0.5$, subject to self-weight and increasing lateral loads. 


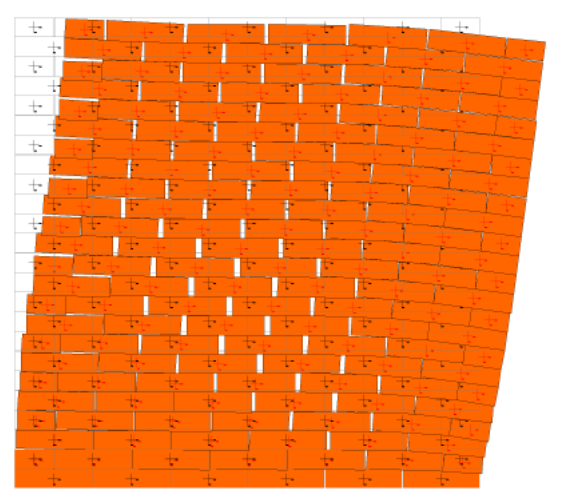

$$
\mathrm{b} / \mathrm{a}=4
$$
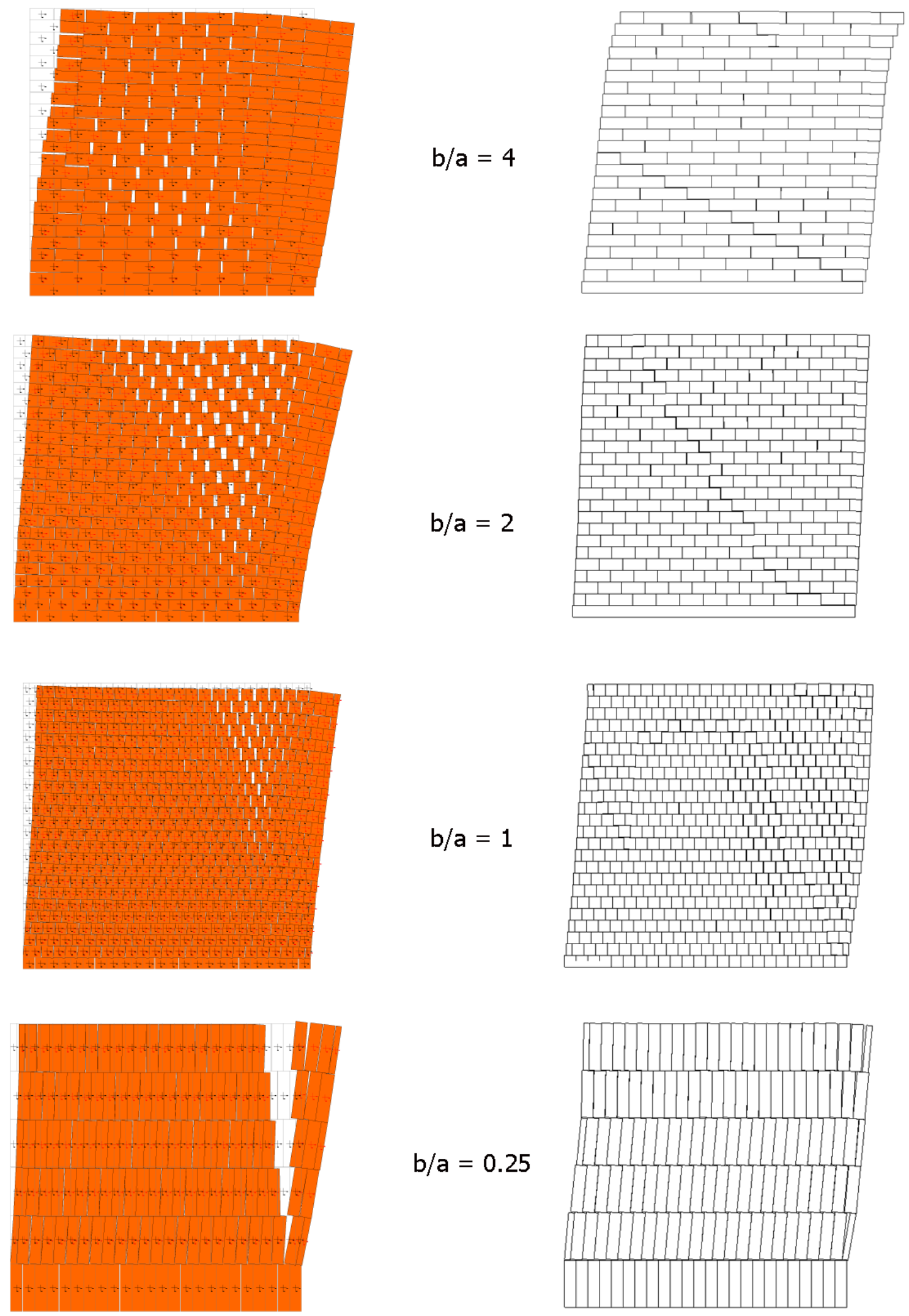

$b / a=2$

$b / a=0.25$

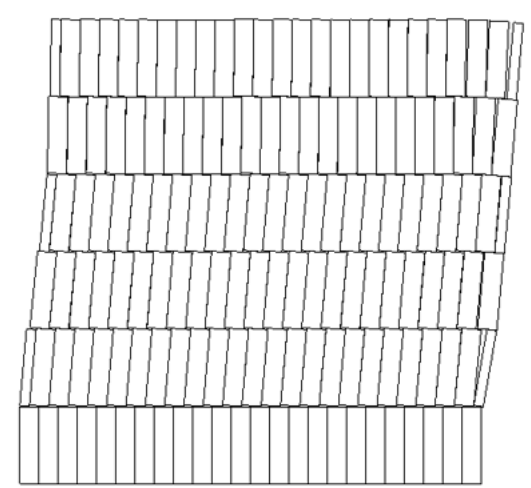

Figure 9: Collapse mechanisms of masonry panels with $H / L=1$, subject to self-weight and increasing lateral loads. 

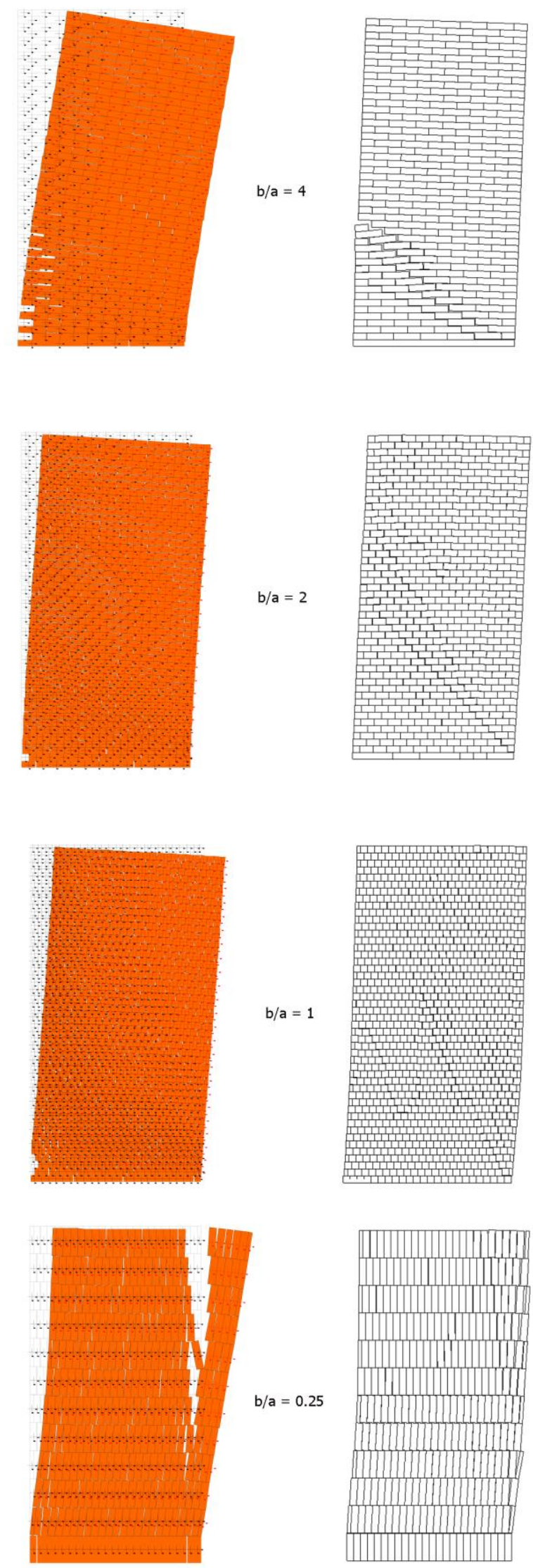

Figure 10: Collapse mechanisms of masonry panels with $H / L=2$, subject to self-weight and increasing lateral loads. 


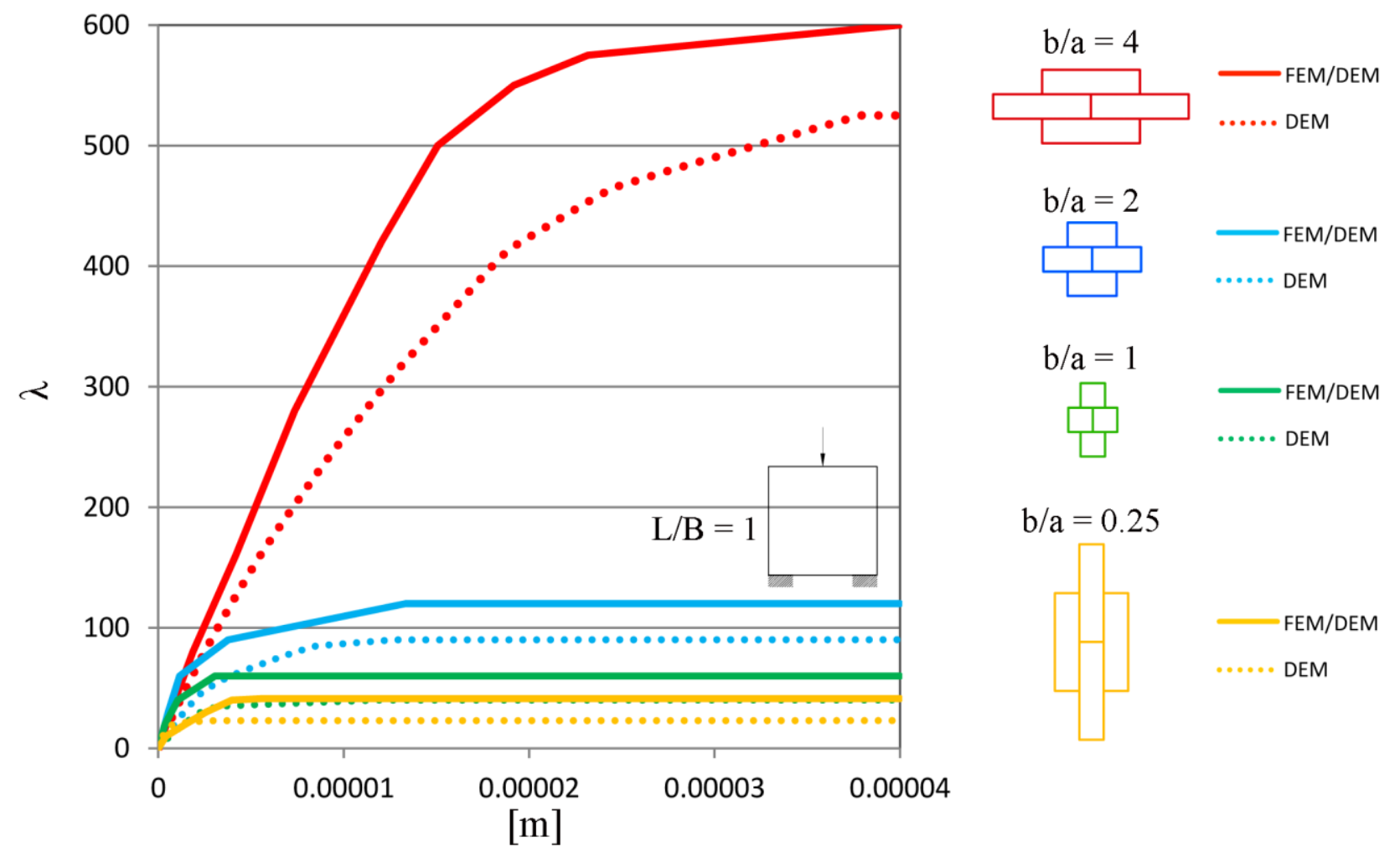

Figure 11: Incremental analyses for square panels subject to an increasing vertical load at the upper edge midpoint. Load vs. vertical displacement. 


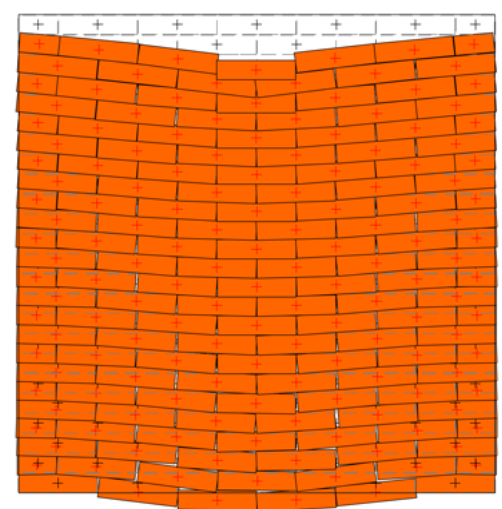

$\mathrm{b} / \mathrm{a}=4$
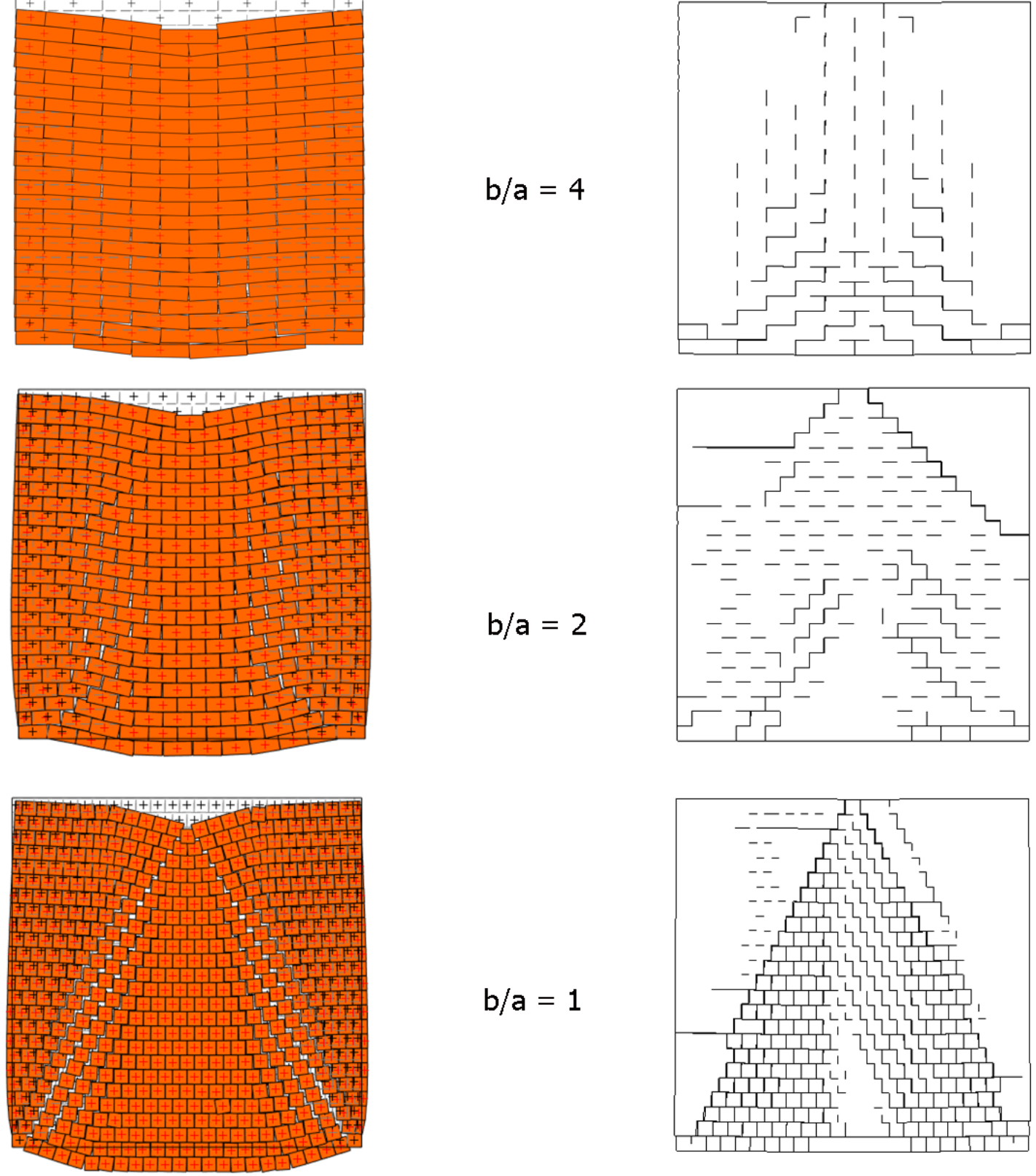

$\mathrm{b} / \mathrm{a}=1$
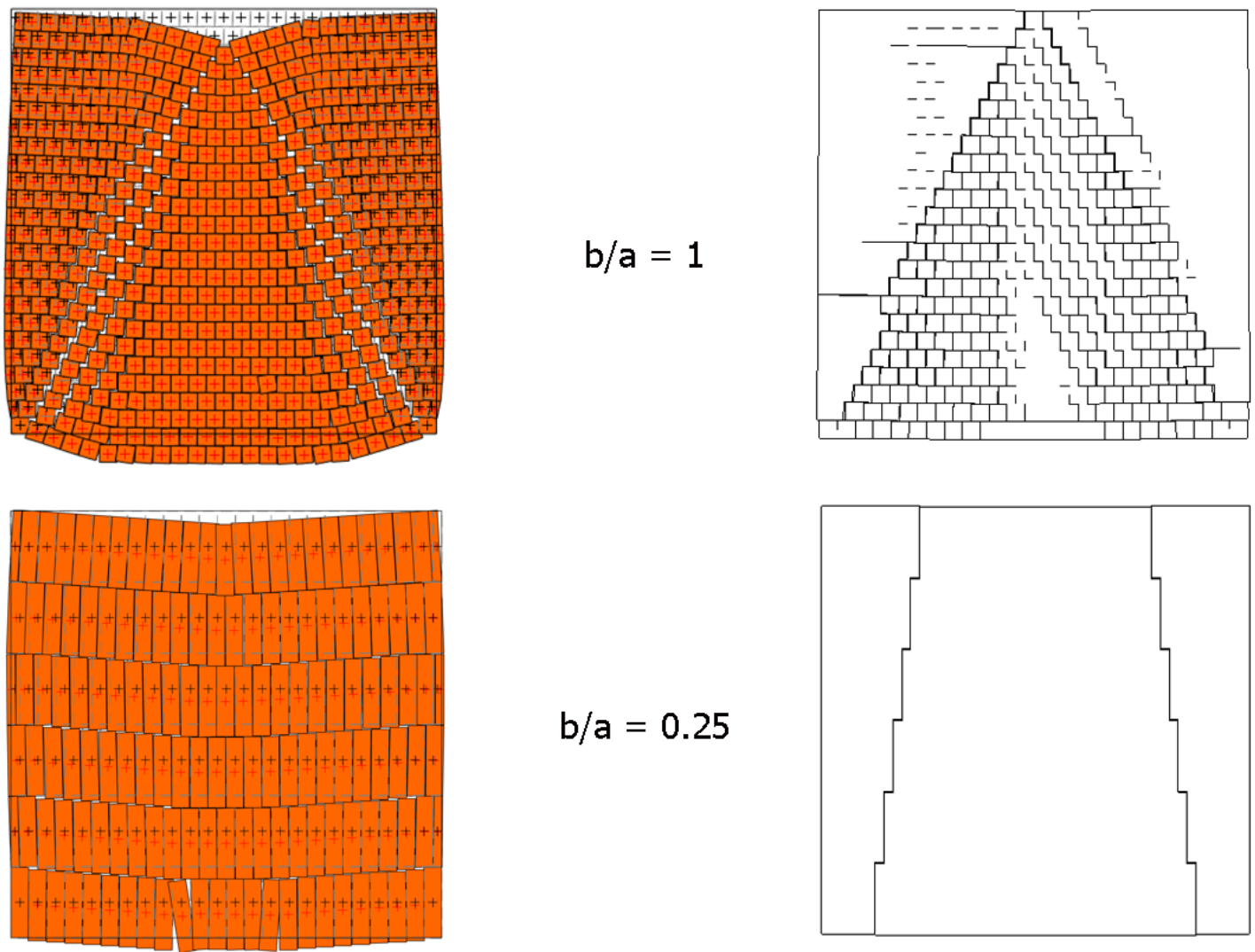

Figure 12: Collapse mechanisms of square panels subject to an increasing vertical load at the upper edge midpoint. 


\begin{tabular}{|c|c|c|c|c|c|c|}
\hline case & $\begin{array}{c}L \\
{[\mathrm{~mm}]}\end{array}$ & $\begin{array}{c}H \\
{[\mathrm{~mm}]}\end{array}$ & $\begin{array}{c}b \\
{[\mathrm{~mm}]}\end{array}$ & $\begin{array}{c}a \\
{[\mathrm{~mm}]}\end{array}$ & $n_{1}$ & $n_{2}$ \\
\hline 1 & \multirow{12}{*}{1440} & 720 & \multirow{3}{*}{240} & \multirow{3}{*}{60} & 6 & 12 \\
\hline 2 & & 1440 & & & 6 & 24 \\
\hline 3 & & 2880 & & & 6 & 48 \\
\hline 4 & & 720 & \multirow{3}{*}{120} & \multirow{3}{*}{60} & 12 & 12 \\
\hline 5 & & 1440 & & & 12 & 24 \\
\hline 6 & & 2880 & & & 12 & 48 \\
\hline 7 & & 720 & \multirow{3}{*}{60} & \multirow{3}{*}{60} & 24 & 12 \\
\hline 8 & & 1440 & & & 24 & 24 \\
\hline 9 & & 2880 & & & 24 & 48 \\
\hline 10 & & 720 & \multirow{3}{*}{60} & \multirow{3}{*}{240} & 24 & 3 \\
\hline 11 & & 1440 & & & 24 & 6 \\
\hline 12 & & 2880 & & & 24 & 12 \\
\hline
\end{tabular}

Table 1: Case studies considered with the corresponding panel dimensions, block dimensions and block number along plane directions.

\begin{tabular}{|c|c|c|c|c|c|}
\hline case & $H / L$ & $b / a$ & $\lambda_{\text {FEM/DEM }}$ & $\lambda_{\mathrm{DEM}}$ & $\lambda_{\text {номо }}$ \\
\hline 1 & \multirow{4}{*}{0.5} & $4 / 1$ & 0.500 & 0.570 & 0.537 \\
\hline 2 & & $2 / 1$ & 0.410 & 0.390 & 0.380 \\
\hline 3 & & $1 / 1$ & 0.310 & 0.260 & 0.269 \\
\hline 4 & & $1 / 4$ & 0.310 & 0.160 & 0.134 \\
\hline 5 & \multirow{4}{*}{1.0} & $4 / 1$ & 0.380 & 0.390 & 0.537 \\
\hline 6 & & $2 / 1$ & 0.320 & 0.310 & 0.380 \\
\hline 7 & & $1 / 1$ & 0.225 & 0.230 & 0.269 \\
\hline 8 & & $1 / 4$ & 0.140 & 0.110 & 0.134 \\
\hline 9 & \multirow{4}{*}{2.0} & $4 / 1$ & 0.240 & 0.330 & 0.372 \\
\hline 10 & & $2 / 1$ & 0.220 & 0.310 & 0.328 \\
\hline 11 & & $1 / 1$ & 0.175 & 0.200 & 0.267 \\
\hline 12 & & $1 / 4$ & 0.130 & 0.094 & 0.134 \\
\hline
\end{tabular}

Table 2: Comparison between ultimate load multipliers for masonry panels subject to self-weight and increasing lateral loads. 